\title{
New rootstocks stop vineyard pest for now
}

$\mathrm{T}$ he phylloxera insect that threatened to devour California's North Coast wine industry has been thwarted - for now. UC scientists and growers have identified rootstocks resistant to the yellow, aphidlike insect, and replanting is well underway in Napa and Sonoma counties.

But scientists warn the solution may only be temporary. "The bottom line is that we still do not know how phylloxera kills grapevines," says Jim Wolpert, chair of the UC Davis Department of Viticulture and Enology, and head of a special UC task force set up to deal with the phylloxera infestation.

The problem began in 1983 when the popular AxR\#1 rootstock, for decades resistant to phylloxera, began to succumb to attack by a new form of the insect called biotype B. AxR\#1 is a cross between the American species Vitis rupestris and the European species Vitis vinifera. Since phylloxera is native to the eastern United States, and coevolved with wild grape species there, American species and their hybrid offspring are resistant to the insect's attack and for 100 years have provided the only known control; there is no known chemical or biological control.

With the ever-growing evidence that AxR\#1 had become susceptible, UC pulled its recommendation for use of the rootstock in 1989. Today, scientists have identified many rootstocks resistant to biotype $\mathrm{B}$. Teleki $5 \mathrm{C}$ is the most popular, currently used in half of the replantings. It is also common in Europe. "We can't guarantee anything but it's probably going to prove resistant for a long, long time," says Jeffrey Granett, UC Davis entomologist.

However, recent evidence from Germany indicates that even highly resistant rootstocks may become susceptible under some circumstances. While Teleki $5 \mathrm{C}$ is proving resistant here, grape growers in Germany report it is showing some susceptibility to phylloxera.

"The new, more aggressive phylloxera in Germany have been found where the soils are shallow and rocky and the vines have been water stressed," says Granett. "Tests indicate this strain is very different from all tested California strains."

Germany's experience is worth noting, however. Most rootstocks are not completely immune to phylloxera, they are resistant to a degree. If grapevines are stressed by drought, disease or other factors, or if the high genetic variability of phylloxera gives rise to a more virulent biotype, the level of resistance or susceptibility can change.

Recent UC research indicates that phylloxera is more genetically variable than previously thought (see p. 9). If field populations are high enough, the potential for selecting damaging biotypes increases. Scientists now believe that wherever older "biotype A" populations exist, there is the potential for biotype $B$ to emerge.

If a formerly resistant rootstock fails, the short-term economic outlook can be grim. Infested vines stop producing after 2 to 3 years; grape growers normally expect each vineyard to have a 25- to 30-year lifespan. It takes new vines 3 to 5 years to bear. The recent wave of phylloxera will cost growers $\$ 15,000$ to $\$ 25,000$ per acre, including replanting expense. In Napa and Sonoma counties, virtually all AxR\#1 vineyards must be replanted. That's 50,000 acres representing 60 to $70 \%$ of the vineyards in those counties. The cost: $\$ 750$ million to $\$ 1.25$ billion.

There is a silver lining, however. Not only are growers reaping record prices for their grapes, providing

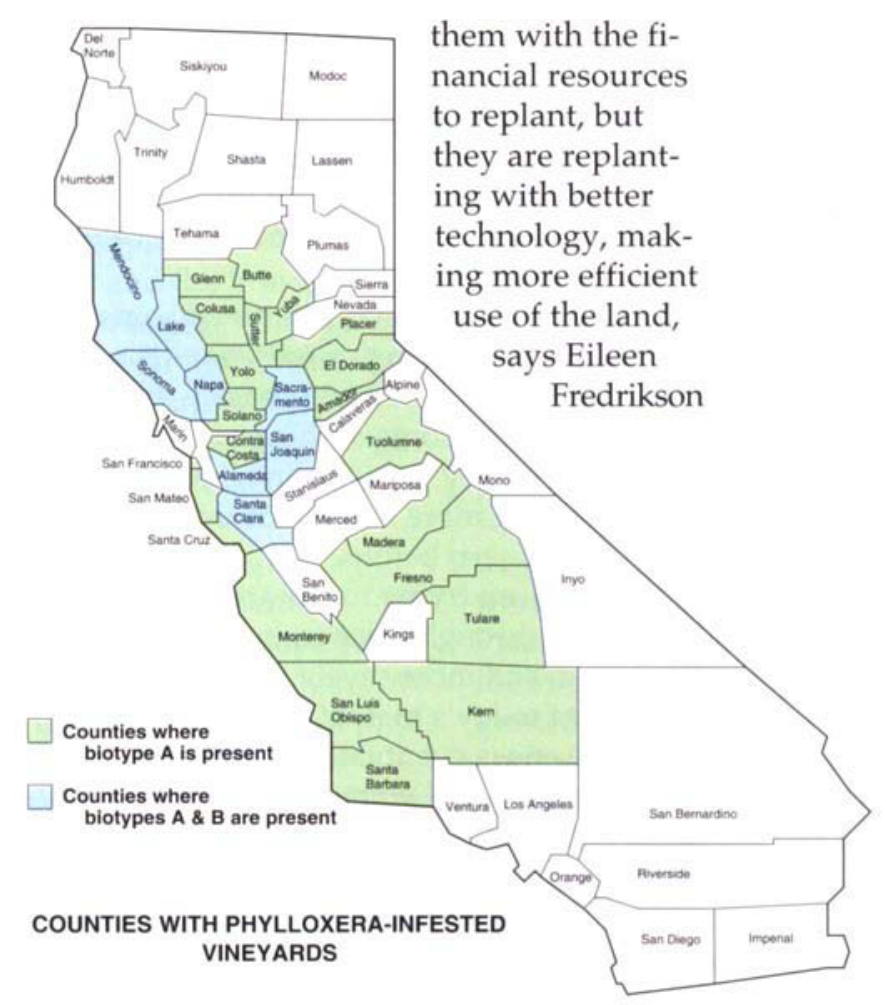




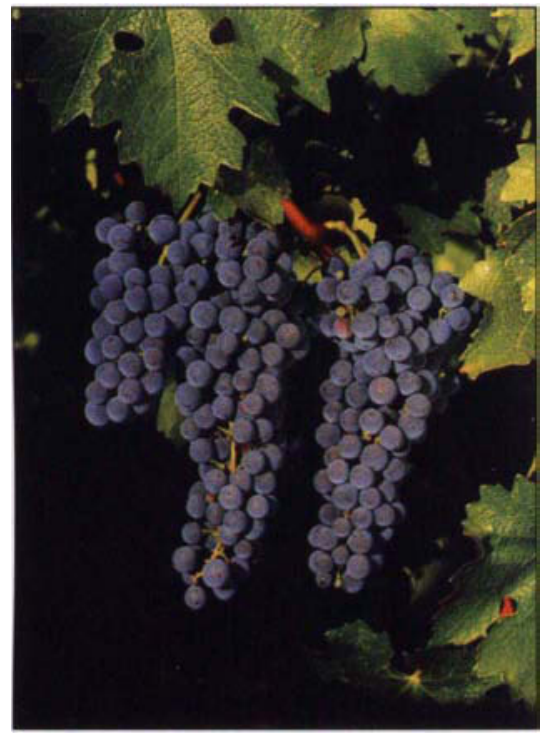

Phylloxera has afflicted grape vineyards for more than 140 years. There is no known chemical or biological control. of Gomberg, Fredrikson and Associates, a wine consulting firm in San Francisco. "The net effect is going to be positive," she says. "The strong market for wine has brought lenders back with a vengeance."

According to a survey of about $60 \%$ of the state's winemakers conducted annually by Deloitte \& Touche LLP, an international accounting firm, average wine industry earnings before taxes as a percentage of sales were $10.6 \%$ in 1995 , compared to $7.7 \%$ in 1994 and $4.5 \%$ in 1993.

Return on equity for investors was $14 \%$ in $1995,10.2 \%$ in 1994 and $5.6 \%$ in 1993.

Consumer demand has soared at a time when wine inventories are low. The demand is causing a boom market in grapes, which are scarcer this year than usual in part because of weather, phylloxera and a decrease in planted acreage. The price per ton of grapes in Sonoma County has risen dramatically. For instance, a ton of cabernet sauvignon sold for $\$ 416$ in 1980 , but $\$ 1,261$ in 1995. Merlot shot up from $\$ 405$ per ton in 1980 to $\$ 1,476$ in 1995 , according to a Sonoma County Agricultural Crop Report.

Industry analysts call it a "renaissance" and it will inevitably put the pinch on consumers who prefer premium California wines. Although no price comparisons were available, analysts agree that the price of wine has increased.

The fierce market has prompted some growers to delay replanting of AxR\#1 rootstock, says Rhonda Smith, UC viticulture farm advisor. Smith notes that some of this year's contracts are so high, "they defy the imagination. Growers are getting more money for their crop than they've ever seen before."

Growers are trying to slow the decline of their vines through more frequent watering, fertilizing, and more severe pruning to take advantage of today's market for grapes.

AxR\#1 vines eventually will have to come out, however. And vineyard managers are faced either with pulling out the old vines, then starting over, or interplanting resistant rootstock in between existing vineyard rows or between vines within rows, in effect establishing a new vineyard before the old one must be pulled out.
Scientists trying to understand phylloxera and its interaction with the grapevine say they still don't know enough about its biology, life cycle, or how some grape species resist its feeding. Some 50 phylloxera research projects have been undertaken by UC in the last 15 years. The research has ranged from developing tests to help growers identify AxR\#1 rootstock, to learning about the bug's genetic ability to adapt and evolve. "What we're trying to do is present a root system the bug does not view as food," says Wolpert.

Much more needs to be known about the genetics of the bug, including its ability to adapt and evolve into different strains and biotypes. To date, three biotypes have been identified: biotype $A$, which is native to eastern North America and can destroy own-rooted vines; biotype B; and Harmony biotype, capable of destroying Harmony rootstock.

Biotype $A$ is more common, found in 30 counties in the state, and presents a problem for own-rooted vines. Biotype $B$, which is destroying AxR\#1, is found in Lake, Mendocino, San Joaquin, Sacramento, Alameda and Santa Clara counties, in addition to Napa and Sonoma (see map). "We don't really know what conditions accelerate or slow its spread," Granett says.

Researchers have investigated the use of soil fumigants, applying them to infested vineyards to see if they can slow down the destruction of the rootstock (see p. 19). Another project involves computer processing of airborne imagery for improved detection and monitoring of plant stress due to phylloxera and other factors (see p. 14).

At UC Davis, geneticist Andrew Walker is conducting breeding trials to find a rootstock resistant not only to phylloxera but to other lifethreatening pests, such as nematodes, viruses and fungi.

To breed phylloxera resistance into a plant, scientists need to know more about the interactions of all the organisms involved. This includes finding out what the insect gets from the plant, what causes the plant to react the way it does, and how other soil organisms contribute to the death of the rootstock.

Both Granett and Wolpert believe growers and researchers need to learn from history or be doomed to repeat it. "The biggest threat is complacency," says Wolpert. "No biological problem can ever be declared to be whipped."

- Valerie Sullivan 